Transportation Research Forum

Investments under Uncertainty in Air Transportation: A Real Options Perspective Author(s): Bruno Miller and John-Paul Clarke

Source: Journal of the Transportation Research Forum, Vol. 44, No. 1 (Spring 2005), pp. 61-74

Published by: Transportation Research Forum

Stable URL: http://www.trforum.org/journal

The Transportation Research Forum, founded in 1958, is an independent, nonprofit organization of transportation professionals who conduct, use, and benefit from research. Its purpose is to provide an impartial meeting ground for carriers, shippers, government officials, consultants, university researchers, suppliers, and others seeking exchange of information and ideas related to both passenger and freight transportation. More information on the Transportation Research Forum can be found on the Web at www.trforum.org. 


\section{INVESTMENTS UNDER UNCERTAINTY IN AIR TRANSPORTATION: A REAL OPTIONS PERSPECTIVE}

Infrastructure investment decisions in air transportation are difficult because of long lead times, large capital expenditures and the technological, market and political uncertainties inherent in aviation. In such an environment, a flexible investment strategy is a means of managing risk. The central idea is to structure the investment so that it would benefit from the upside potential if circumstances are resolved favorably, but would be protected from downside losses otherwise. In this paper, an evaluation methodology based on system dynamics and Monte Carlo simulation in a real options framework is utilized to evaluate different flexible infrastructure delivery strategies.

\section{by Bruno Miller and John-Paul Clarke}

Air transportation is a cyclical industry characterized by periods of strong growth followed by periods of deep capacity reductions and other desperate measures by airlines to remain operational (Skinner et al., 1999; Stonier, 1999). Planning in the face of this volatility becomes a major problem for many stakeholders, in particular airports and aircraft manufacturers. Because of the large capital requirements and long lead times generally associated with new runways, passenger buildings, or aircraft assembly lines, the timing of these investments is of particular importance. A premature investment may result in unused capacity that sits idle without generating any returns whereas a tardy investment may miss the potential market completely.

A flexible approach for infrastructure delivery is a means of managing the risk associated with these types of endeavors. The central idea is to structure the project so that it would benefit from the upside potential if circumstances are resolved favorably, but would be protected from downside losses otherwise. Traditional evaluation techniques, such as the net present value (NPV) rule or decision analysis (DA), may not always be appropriate to determine the value of such strategies. In this paper, a new methodology to determine the strategic value of air transportation infrastructure based on Monte Carlo simulation and system dynamics in a real options framework is presented. This methodology is illustrated by considering a simple, yet common, situation where a service facility (e.g., a runway, a passenger building, etc.) has fixed capacity and stochastic demand.

The objective of this research is to develop a methodology to support investment decisions in air transportation infrastructure by determining the value of flexible capacity-expansion strategies. Two main hypothesis underlie this work: first, that the value of flexibility arises from the coupling of internal (project) dynamics to external (market) dynamics. This suggests using systems dynamics as a modeling tool. Second, that the value of flexibility also arises from uncertainties related to the technology and market conditions. This merits the use of Monte Carlo simulation to take multiple sources of uncertainty into account.

In the second section, some difficulties with traditional valuation methodologies are highlighted. In the third and fourth sections, a brief overview of financial and real options, respectively, is given. In the fifth section, the evaluation of real options with uncertain exercise price is introduced. In the sixth section, the methodology proposed here is explained. In the seventh section, an airport capacity expansion project is used as an example to demonstrate this methodology. In the eighth section, numerical results are presented. In the ninth and final section, conclusions are presented. 


\section{DIFFICULTIES WITH TRADITIONAL VALUATION METHODOLOGIES}

Traditional evaluation methodologies such as the net present value rule and decision analysis may not always be appropriate for determining the value of flexibility in the face of uncertainty. In the NPV rule, the investment decision must be made with information available today (Copeland and Antikarov, 2001). Therefore, there is no explicit consideration of the effects of managerial flexibility on the outcome of the investment. For example, at the point of project evaluation, cash flows are assumed to occur at fixed points in time. Thus, while uncertainties related to the magnitude of the cash flows can be determined with different methods, e.g., Monte Carlo simulation, there is no possibility to incorporate changes in the schedule of cash flows that might result from managerial actions. Decision analysis is an improvement over the NPV rule in terms of being able to explicitly incorporate the effect of flexibility into the decision framework, because, by using decision trees, it is possible to assign probabilities to different outcomes at certain points in time (Amram and Kulatilaka, 1999). Thus, DA can be used to find the value of flexibility in many situations. However, if there are many sources of uncertainty, which is the case in many large infrastructure investments, the number of paths in the tree expands geometrically with the number of decisions and states considered for each variable (Trigeorgis, 1996). In such a case, the evaluation of the project with DA may become onerous.

In the past decade, real options analysis (ROA) has emerged as an alternative project valuation technique. It is based on financial options theory but, instead of finding the value of holding an option on a financial asset, it is applied to "real" projects to estimate the value of flexibility in the face of uncertainty (Dixit and Pindyck, 1994). ROA is related to the NPV rule and decision analysis to the extent that they all use discounted cash flow (DCF) to different degrees in the evaluation of future cash flows. However, ROA can offer advantages over the NPV rule and DA by explicitly accounting for flexibility and multiple sources of uncertainty in a compact manner.
In the next section, the fundamental concepts of financial options are explained. This discussion is useful to understand the basics of real options presented afterwards.

\section{BASICS OF FINANCIAL OPTIONS}

Financial options are securities that give the option owner the right, but not the obligation, to buy or sell an asset at a pre-determined price within a specified period of time (Black and Scholes, 1973). The price paid for the asset when the option is exercised is called the "exercise price" or "strike price." The last day on which the option may be exercised is called the "expiration date" or "maturity date." A "European option" can only be exercised on the expiration date; an "American option" can be exercised at any time up to the maturity date.

If an investor owns an option, the owner is able to defer the decision to fully invest until more information is available about the state of the world. Thus, the investor can protect against downside losses by only investing when conditions are favorable.

The payoff of a European call option, w, on a non-dividend paying stock is shown in Figure 1. ${ }^{1}$ If the stock price, $\mathrm{S}$, is less than the strike price, $\mathrm{X}$, the option does not get exercised and the payoff is zero. However, if $\mathrm{S}$ is larger than $\mathrm{X}$, the option holder has the option of buying the stock for $\mathrm{X}$ and then selling it for $\mathrm{S}$, thus making a profit of S-X. Mathematically, the payoff of a call option can be expressed as the maximum of $\mathrm{S}-\mathrm{X}$ or zero, i.e., $\max [\mathrm{S}-\mathrm{X}, 0]$. This profit must be compared to the cost of obtaining the option to determine the net profit.

Options are valuable because the future stock price is uncertain (see Figure 2). In fact, the value of an option increases with the volatility of the stock, because this means that the stock can reach higher prices (it can also reach lower prices, but this is not of concern because the option protects the investor from downside movements).

\section{BASICS OF REAL OPTIONS}

Real options analysis (ROA) uses some of the basics of financial options theory to find the value of options in "real" projects. For example, 
Figure 1: Payoff of a European Call Option on a Non-Dividend Paying Stock, $S$

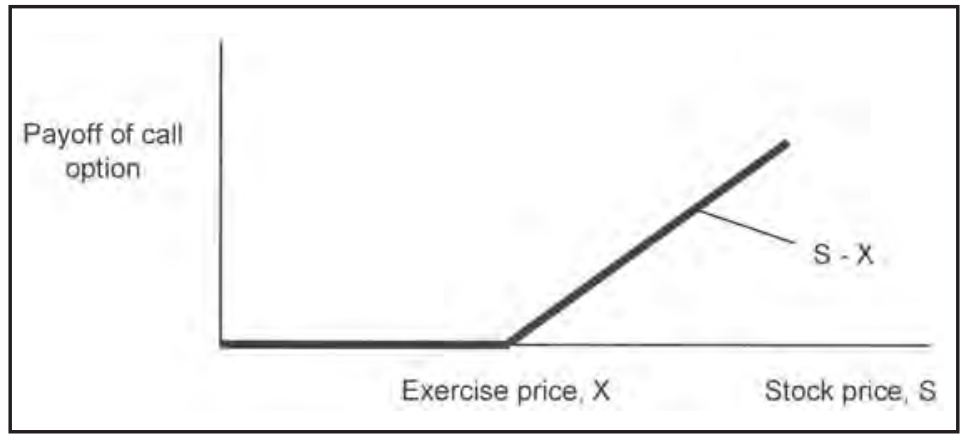

Source: Authors with information from Brealey and Myers (1996)

Figure 2: The Stochastic Nature of Stock Prices Make Options Valuable

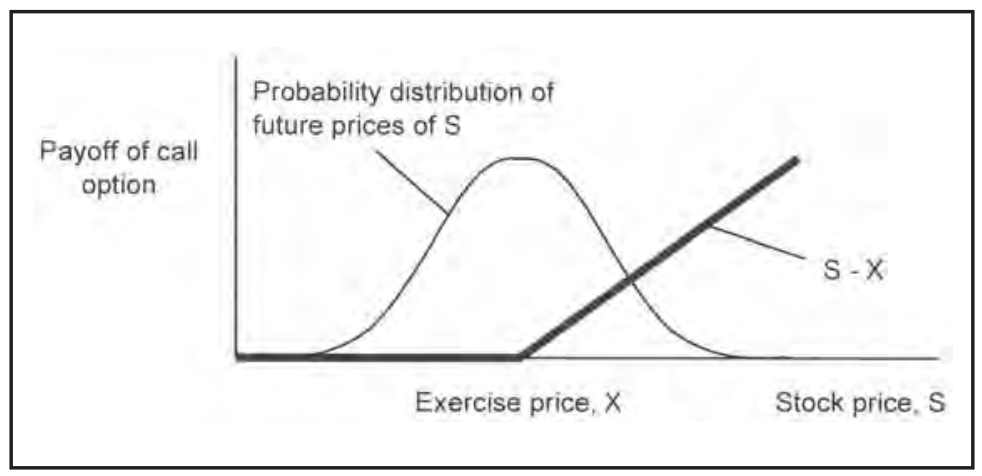

Source: Authors with information from Brealey and Myers (1996)

consider a city that is contemplating building a new airport. Assume further that current levels of demand require only one runway, but there are indications that future demand may grow to levels where a second runway could be necessary. A prudent strategy in this case would be to build the first runway and acquire the land for the second runway now, then wait until traffic levels increased significantly before building the second runway.

Ownership of the land for the second runway gives the airport developers the right, but not the obligation, of expanding capacity if and when it is needed. In this manner, the additional capacity of the second runway can be realized more quickly than in a case where one runway was built but no land was purchased, thus increasing the likelihood that the second runway would be better timed with the market. Another approach would be to build both runways now.
However, given uncertainties in demand, there is a risk that the second runway may not be needed. The option to build the second runway offers protection against this situation.

Creating and having the option comes at a price: the airport developer must buy a piece of land. This is where ROA can be particularly useful because it can help to determine the value of this option and, hence, indicate the maximum price that an investor should be willing to pay for it.

\section{EVALUATING REAL OPTIONS WITH VARYING STOCK PRICE AND STRIKE PRICE}

Most traditional financial option methodologies assume that the strike price is fixed a priori and does not change throughout the life of the option. While this may be a valid assumption 
for financial options, it is not necessarily true for real projects because the strike price of real options (generally taken to be a cost related to the project, such as capital investments and/or operational or maintenance expenditures) can certainly vary over time.

There are a few examples in the financial options literature that address the valuation of options when the strike price is uncertain. Stanley Fischer (1978) and Dixit and Pindyck (1994) assume that the strike price can be represented by a geometric Brownian motion (GBM) and use this behavior to derive their analytical evaluation formulae. While GBMs may be appropriate to model the behavior of stock and strike prices for financial options, expected revenues and costs of real projects do not necessarily follow these type of stochastic processes.

An approach from the ROA literature that can be used to evaluate real options with uncertain exercise prices is given by Robert Tufano and Alberto Moel (1997) (referred to as the "Tufano-Moel approach" here). Their technique consists of simulating the value of the underlying asset until the end of the life of the project, assuming that the real option is always exercised, and then finding its present value. This process is repeated thousands of times using Monte Carlo simulation to incorporate multiple sources of uncertainty both on revenues as well as on costs. In this manner, a distribution of net present values for the project with its associated mean is obtained (Figure 3, left).

The power of real options is that they allow managers to abandon projects with negative outcomes. Tufano and Moel (1997) argue that this can be represented by substituting negative NPVs with zero which essentially truncates the distribution (Figure 3, right). Further, they argue that the mean of this truncated distribution is the value of the project with flexibility, and that the value of the real option is the difference between the means with and without flexibility.

\section{REAL OPTIONS, SYSTEM DYNAMICS AND MONTE CARLO SIMULATION}

The methodology proposed by Tufano and Moel can be used to find the value of real options when the exercise price is uncertain by simulating the expected net present values. Here, an alternative approach is proposed that combines the power of simulation with the simplicity of analytical solutions. As in the case of Tufano and Moel, the methodology developed here assumes a European call-like real option.

First, assume that the probability density function, $\mathrm{f}_{\mathrm{s}}(\mathrm{s})$, of the expected revenues from a real project (i.e., the stock price, $S$ ) at expiration time $\mathrm{T}$ is known. In addition, assume that the cost of exercising a real option on this project (i.e., the strike price, $\mathrm{X}$ ) at expiration time $\mathrm{T}$ is also known (Figure 4).

In this case, the decision-maker would only exercise in those instances when the stock price (expected revenues) is greater than the strike price (exercise costs). The value of this option, w, can be calculated as the difference of two terms. The first term is the expected value of revenues given that the revenues are realized, i.e., given that the option is exercised (Hull, 2000). Since the option would only be exercised if the stock

Figure 3: Sketch of the Approach Proposed by Tufano and Moel to Evaluate Real Options
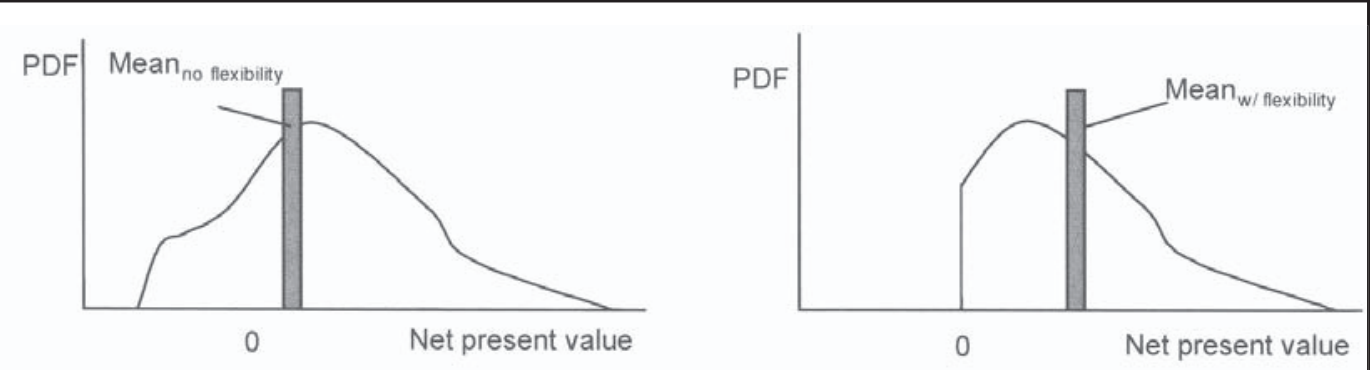

PDF: Probability Density Function

Source: Authors with information from Tufano and Moel (1997) 
price is higher than the strike price, this expected value can be represented as the expected value of $\mathrm{S}$ for values of $\mathrm{s}>\mathrm{X}$ (see first term in Equation 1). The second term represents the costs associated with exercising the option. It can be computed as the strike price, $\mathrm{X}$, weighted by the probability that it is realized, i.e., the likelihood that the option is exercised (Chriss, 1997). This can be expressed as $\mathrm{X}$ times the probability that $\mathrm{X}$ will be incurred, i.e., the probability that $\mathrm{s}>$ $\mathrm{X}$ (second term in Equation 1):

(1) $w=\int_{s}^{\infty} s \cdot f_{S}(s) d s \quad X \cdot \int_{S}^{\infty} f_{S}(s) d s$
In reality, however, exercise costs can also be uncertain. Therefore, assume that the expected exercise cost at time $\mathrm{T}$ can be described with a probability distribution, $\mathrm{f}_{\mathrm{x}}(\mathrm{x})$ (Figure 5).

Consequently, the value of the option, $w$, is now a random variable dependent on $\mathrm{x}$ (see Equation 2):

(2) $w=w(x)=\int_{s}^{\infty} s \cdot f_{S}(s) d s-x \cdot \int_{s}^{\infty} f_{S}(s) d s$

The expected value of $\mathrm{w}$ can be determined by applying the definition of expected value for continuous random variables (see Equation 3):

$$
E[w(x)] \int_{x=\infty}^{x=\infty} w(x) \cdot f_{x}(x) d x=\int_{x=0}^{\infty} f_{x}(x) \int_{s=x}^{\infty} s \cdot f_{s}(s) d s d x-\int_{x=0}^{\infty} x \cdot f_{x}(x) \cdot \int_{s=x}^{\infty} f_{s}(s) d s d x
$$

Figure 4: Probability Distribution of Expected Revenues, S, and Fixed Construction Costs, X, at Time T

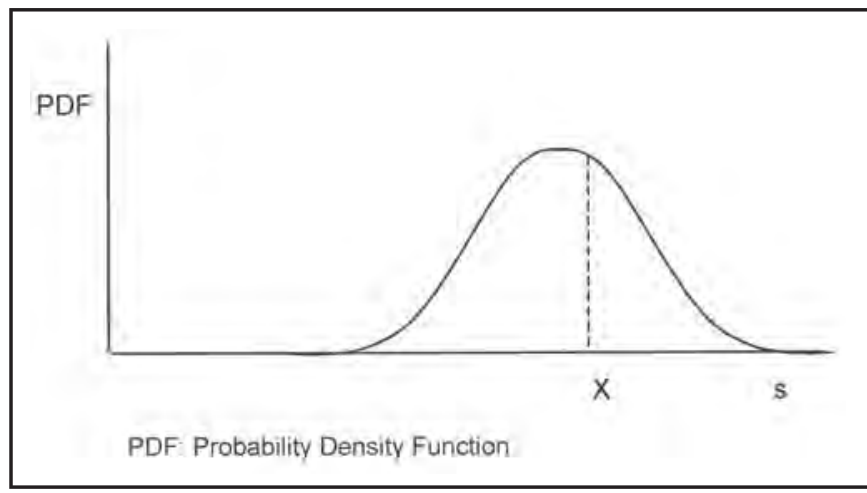

Figure 5: Probability Distribution of Expected Revenues, S, and of Construction Costs, X, at Time T

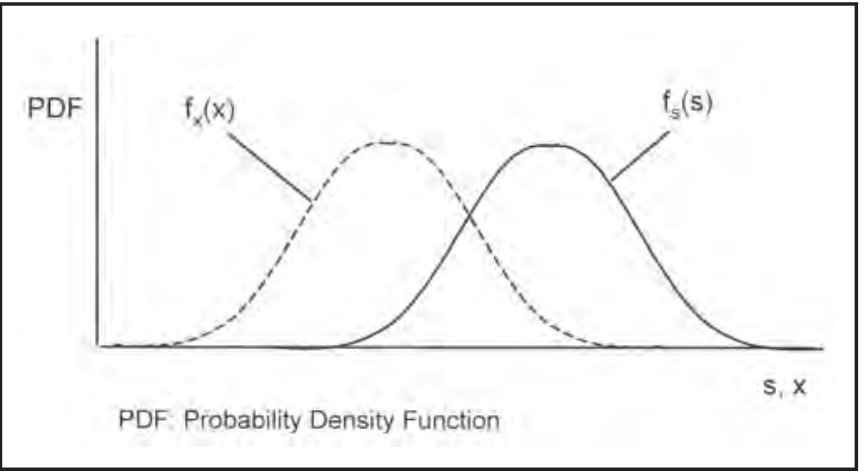


If all values of $s$ are larger than all values of $x$, the real option will be exercised with great certainty and its value is given by the above result. This is analogous to the value of financial European call options when $\mathrm{S}$ is much larger than $\mathrm{X}$, in which case the value of the financial option approaches S - X.

To find the distributions of revenues and costs of the real project to be used in Equation 3 , a combination of system dynamics and Monte Carlo simulation is suggested. System dynamics is a powerful tool to model the internal dynamics, feedback loops and uncertainties of the project and its behavior given external influences. In addition, system dynamics is flexible enough to allow the simulation of other factors such as competitor behavior, if desired. Monte Carlo simulation can be combined with the system dynamics model to obtain a better representation of the cash flows by including the effects of different sources of uncertainty.

An advantage of this methodology over other analytical approaches, such as the ones proposed by Fischer (1978) and Dixit and Pindyck (1994), is that the stock and strike price are not restricted to behaving like geometric Brownian motions. These distributions can be of any type and, therefore, can provide a better representation of project value. With respect to the Tufano-Moel approach, the methodology developed here would have the advantage of not being restricted to simulating the behavior of the stock and strike prices. If the distribution of costs and revenues can be expressed analytically, the methodology developed here can find a closed-form solution for the value of the real option. This would not be possible using the Tufano-Moel method. Another potential advantage is the possibility of managing cost for a given demand. For example, if demand is well understood, the formula developed here could be used to find the cost profile that would maximize the value of the project. The Moel-Tufano approach would not be able to do this, either. Nevertheless, if the distributions of stock and strike prices must be obtained with simulation, the methodology developed here and the Moel-Tufano approach would be equally capable of finding the value of the real option.

As stated, this methodology assumes that costs and revenues are independent. This can be a reasonable assumption for those systems where, for example, the couplings between the costs of supplying and maintaining the infrastructure and demand are not very strong. In the case where these couplings may be significant, conditional probabilities would have to be used.

Another important question regarding this evaluation methodology is related to the choice of the discount rate. The valuation formula from Equation 3 gives the expected value of $\mathrm{w}$ at exercise time, $\mathrm{T}$. Thus, to find its value today, it is necessary to discount the distributions of revenues and costs to the present with a risk-adjusted discount rate. This risk-adjusted discount rate could be the cost of capital used by the investor for similar projects or it can be found with traditional methodologies such as the capital asset pricing model (CAPM).

\section{EXAMPLE: AN AIRPORT EXPANSION PROJECT}

The valuation methodology developed here is very flexible and can be applied to many different situations. In particular, this methodology is suitable to evaluate projects where capital investments are large, implementation times are long, and uncertainties are large. Investments in air transportation, such as the construction of new runways, new passenger buildings, or new aircraft programs, share these qualities. Therefore, the example of the city with an interest in building a new airport with one or two runways mentioned previously is used to illustrate the methodology proposed in this paper.

The real option considered here consists of the right, but not the obligation, of building a second runway to obtain the revenues from the demand served by the added capacity. The underlying asset, $\mathrm{S}$, is expected revenues from travel demand served by the second runway. The exercise price, $\mathrm{X}$, is the sum of the construction and maintenance costs of the second runway. The value of the option is the maximum price of the land for the second runway that the project developer would be willing to pay.

This is a real option to expand because by purchasing the land, the option owner acquires the possibility of expanding current infrastructure by building a second runway at a specific 
point in time if demand requires it. Notice that this is not a real option to delay. A real option to delay would assume that the second runway is always built, but at a later date than originally planned. This stands in contrast to the real option to expand where the second runway may never be built.

The purpose of the evaluation methodology is to determine whether the value of the real option (building a second runway) is greater than the cost of the real option (buying the land). If it is, then the city should follow this strategy and purchase the land for the second runway. Several different scenarios are considered to analyze the effect of different maturity times, size of the investment, and time to deliver the investment on project financial performance and on the value of the real option.

\section{Modeling the Airport Expansion Project with System Dynamics}

System dynamics is used to model the airport expansion project (see Figure 6). In this particular example developed by Miller and Clarke (Miller and Clarke, 2003), runway capacity is the limiting factor that leads to congestion. As demand for air travel (aircraft per hour) increases, the total number of aircraft requesting service on this runway (total aircraft) also increases. Demand is modeled as a meanreverting stochastic process according to the process outlined (Dixit and Pindyck, 1994). If runway capacity is held constant, the increase in demand slowly leads to congestion, which raises the direct operating costs of airlines (airline congestion cost). The higher operating costs are passed on to the passenger in terms of higher air fares (air fare impact) and this leads to less demand for travel (congestion cost loop). In addition, congestion decreases the level of service by lengthening passenger travel time (level of service impact) which also results in less demand for aviation services (passenger comfort loop). When the decision to add capacity is taken, i.e., when the option is exercised, a certain amount of capacity (capacity increase) is delivered after a certain period of time (years to increase capacity). The decision to expand capacity is the key managerial intervention in this model. Once capacity is added to the runway, congestion decreases, thus, stimulating demand by reducing the air fare impact and level of service impact. Delivery costs represent the expenditure associated with providing the desired capacity expansion. Maintenance costs are recurring costs associated with maintaining the added capacity. The model assumes that

Figure 6: System Dynamics Model of the Hypothetical Situation Considered in this Study

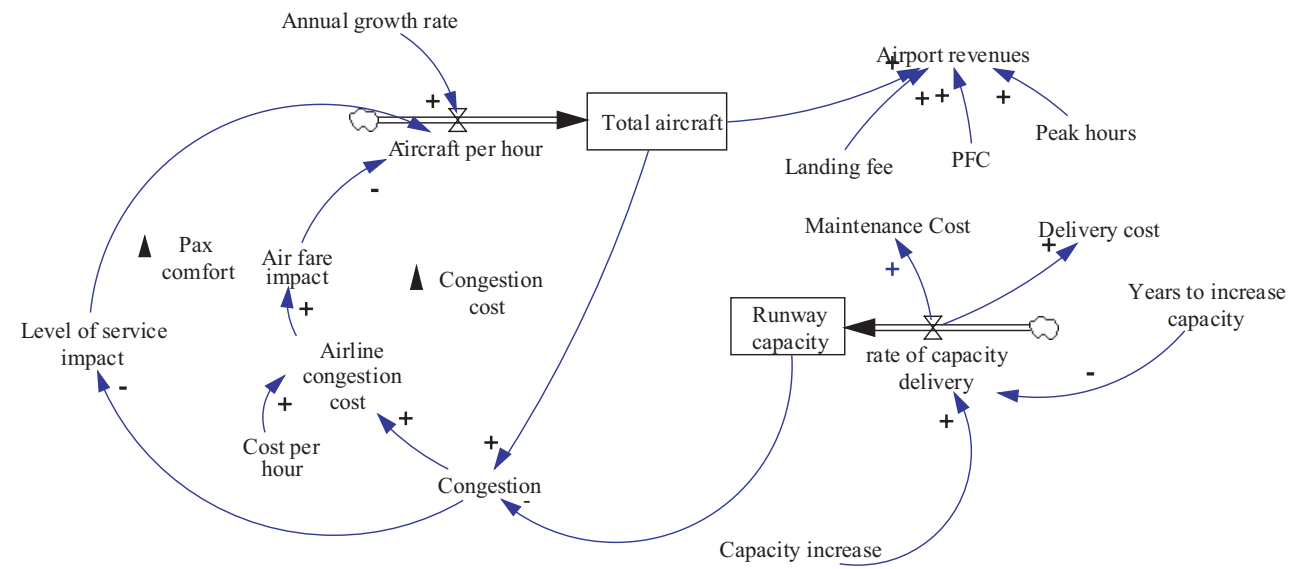

Pax: Passenger

PFC: Passenger facility charges 
congestion occurs only at a given number of peak hours per year.

There are two main outputs from this model. The first are the benefits from the expanded infrastructure accrued to the airport operator in terms of airport revenues. Here, it is assumed that they consist mainly of landing fees paid by the airlines and passenger facility charges $(P F C)$ paid by each traveler. The second output are the costs of infrastructure expansion (delivery cost) and maintenance (maintenance costs) of this expanded infrastructure. These outputs are used to calculate the value of the underlying asset, S, and the exercise price, $X$.

The numbers used to calibrate the model are meant to illustrate a realistic situation but they do not represent an actual airport. The airport in this study is assumed to be a one-runway facility that serves primarily narrow-body aircraft. The current runway capacity was set at 40 aircraft per hour. Landing fees were estimated at $\$ 200$ per aircraft based on data given by de Neufville and Odoni (2003) and the typical weight of narrow-body aircraft. It is further assumed that congestion occurs only at peak hours and there are 1,000 peak hours in a year. The simulation time period is in years and each run covers 30 years. Demand was calibrated using historical data for air travel demand in the United States between 1979 and 2001 contained in the Form 41 database (USDOT, 1979-2001).

Monte Carlo simulation is used in combination with the system dynamics model to take into account multiple sources of uncertainty. The variables in Table 1 were assumed to behave randomly.

A total of 1,000 runs are made in each Monte Carlo simulation.

\section{Infrastructure Delivery Strategies}

Different capacity expansion strategies were analyzed to determine the variation in the value of flexibility. Three parameters were assumed to define an infrastructure delivery strategy: 1) the maturity of the option, 2) the size of the capacity expansion, and 3) the time to deliver the capacity once the decision to expand has been made. For the maturity time, three values were considered: 2,5 , and 10 years. These are the values on the horizontal axis of Figures 7 to 12. The size of the expansion was considered to be small $(25 \%$ of existing capacity), medium (50\% of existing capacity) and large (75\% of existing capacity). Three times to deliver capacity were assumed: 5,7 , and 10 years. The life of all projects was assumed to be 30 years.

\section{The Value of Flexibility}

Here, it is assumed that the value of flexibility is the difference between the value of the flexible strategy and the maximum of the value of the inflexible strategies or zero:

(4) Value of flexibility = Value of flexible strategy - max[Value of inflex. strategy, 0]

The value of the flexible strategy is calculated with Equation 3. The value of the inflexible project is calculated as the mean of the net present values for each run in the Monte Carlo simulation. If the mean NPV of the inflexible strategy is negative, the project would not be undertaken. Thus in this case, the appropriate comparison to find the value of flexibility should be between the value of the flexible strategy as calculated with Equation 3 and zero.

Table 1: Variables Considered for Monte Carlo Simulation and Their Assumed Probability Distributions

\begin{tabular}{|l|l|l|c|c|}
\hline Variable & Units & Prob. Distr. & Min. value & Max. value \\
\hline Average travel time & Hours & Uniform & 2 & 4 \\
\hline Time elasticity & N/A & Uniform & -1.6 & -0.8 \\
\hline Price elasticity & N/A & Uniform & -1.6 & -0.8 \\
\hline Unit Maintenance costs & $\$ /($ aircraft $/ \mathrm{hr})$ & Uniform & 0.6 million & 1 million \\
\hline Unit Delivery costs & $\$ /($ aircraft $/ \mathrm{hr})$ & Uniform & 3 million & 10 million \\
\hline
\end{tabular}




\section{NUMERICAL RESULTS}

\section{Strategies with Small (25\%) Capacity Increase}

Projects that consider a $25 \%$ increase in capacity have, in general, a positive expected NPV (Figure 7). The intuition is that small increases in capacity are sufficient to meet the expected demand. Therefore, there is no need to incur large capital expenditures and the costs can be recovered more rapidly. Another important consideration is the timing of the investment: as the capital delivery is pushed further into the future (in other words, as maturity and/or time to deliver capacity increase), the expected value of the project decreases. Delaying the infrastructure expansion results in the airport not being able to capitalize on the demand that would materialize if the additional capacity was available. For example, the only case where the project has a negative expected NPV is when the maturity is 10 years and it takes 10 years to deliver the capacity. In this situation, capacity is added so late in the life of the project that there are only a handful of periods available to generate revenues and recover the investment.

The value of flexibility for these projects is minimal (Figure 8). Because they are very likely to succeed by following an inflexible strategy, having a flexible approach does not improve their expected value.

\section{Strategies with Medium (50\%) Capacity Increase}

Projects that consider a medium capacity increase are not clear winners. Depending on the maturity of the real option and the time to deliver capacity, the expected NPV of the inflexible strategies may be negative, close to zero, or positive (Figure 9). This indicates that the timing of the infrastructure delivery must be considered carefully. In general, early exercise results in too much capacity relative to demand, thus it is difficult to recover the investment. As the exercise date recedes into the future, demand can grow to levels where the large added infrastructure can be better utilized. Notice, however, that a short time to deliver capacity is always preferable. A long time to deliver capacity may result in the project not being able to generate enough revenues to recover costs or to miss the market completely.

The value of flexibility for these cases is higher than for those projects with $25 \%$ capacity increase (Figure 10). In addition, notice that the value of flexibility is highest for those situations where the expected value of the inflexible project is close to zero. Intuitively, flexibility is most valuable in these circumstances as it can tip the project towards positive outcomes.

\section{Strategies with Large (75\%) Capacity Increase}

Strategies with large capacity increase result in projects with negative expected net present values in almost all situations (Figure 11). In general terms, these strategies lead to excess capacity (over-investment) with a large expenditure that can not be recovered with the expected traffic.

The value of flexibility for projects with large negative expected net present value is zero (Figure 12). Because the performance of these inflexible projects is so poor, flexibility alone is not enough to push them into the positive realm. Notice, however, that the value of flexibility is higher for those projects with an expected NPV close to zero.

\section{APPLICATION TO A REAL-WORLD SITUATION}

The airport example considered here is hypothetical, but it is grounded in the real world. The values used for the system dynamics model and the Monte Carlo simulation are based on typical values observed in practice. The application of the methodology to an actual airport expansion project should therefore be relatively straightforward provided that enough data is available.

There are two major sets of data required to implement this methodology to a real-world airport situation. First, a delay model for the airport is required. This model must be able to quantify flight delays given current runway capacity and current demand. In addition, the delay model must anticipate delays under different capacity expansion scenarios and 
Figure 7: Expected Value of Projects without Flexibility for Strategies that Consider 25\% Capacity Increase and 5, 7, and 10 Years to Increase Capacity

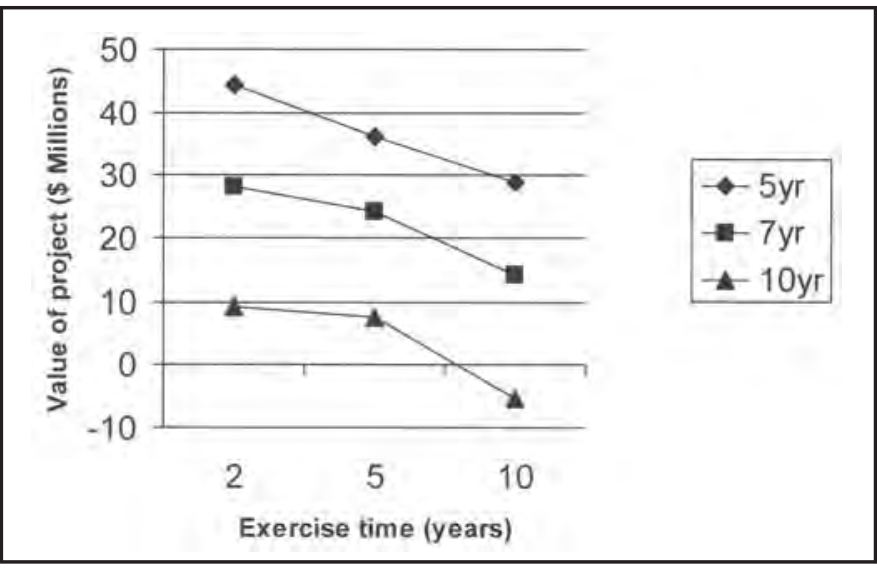

Figure 8: Value of Flexibility for Strategies that Consider $25 \%$ Capacity Increase and 5, 7, and 10 Years to Increase Capacity

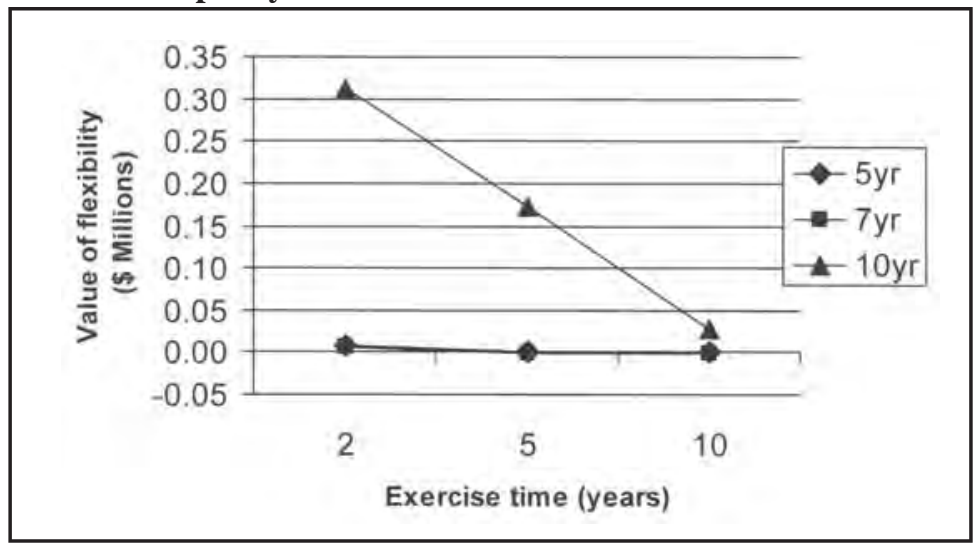

Figure 9: Expected Value of Projects without Flexibility for Strategies that Consider 50\% Capacity Increase and 5, 7, and 10 Years to Increase Capacity

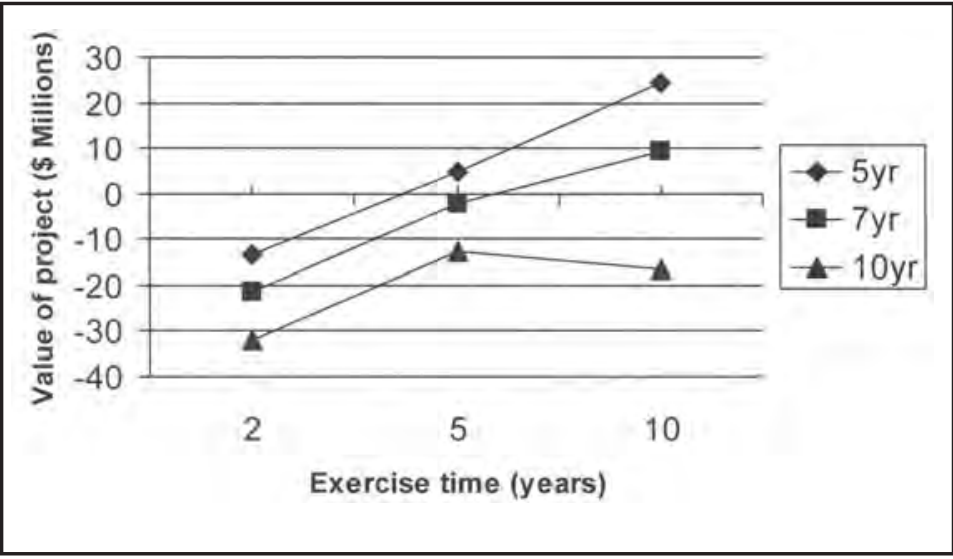


Figure 10: Value of Flexibility for Strategies that Consider $50 \%$

Capacity Increase and 5, 7, and 10 Years to Increase Capacity

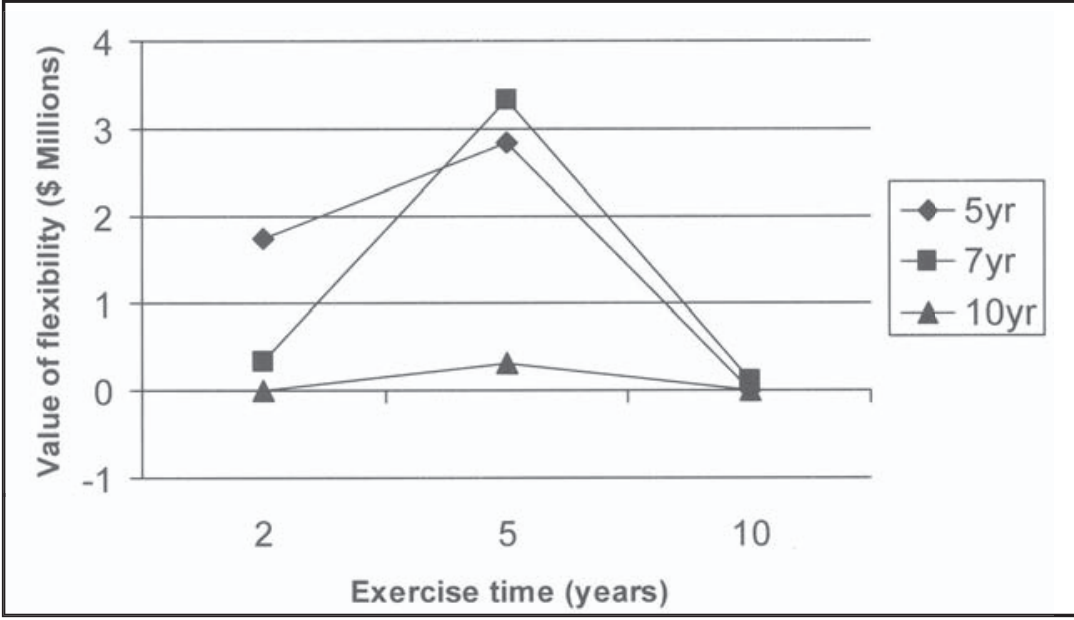

Figure 11: Expected Value of Projects without Flexibility for Strategies that Consider 75\% Capacity Increase and 5, 7, and 10 Years to Increase Capacity

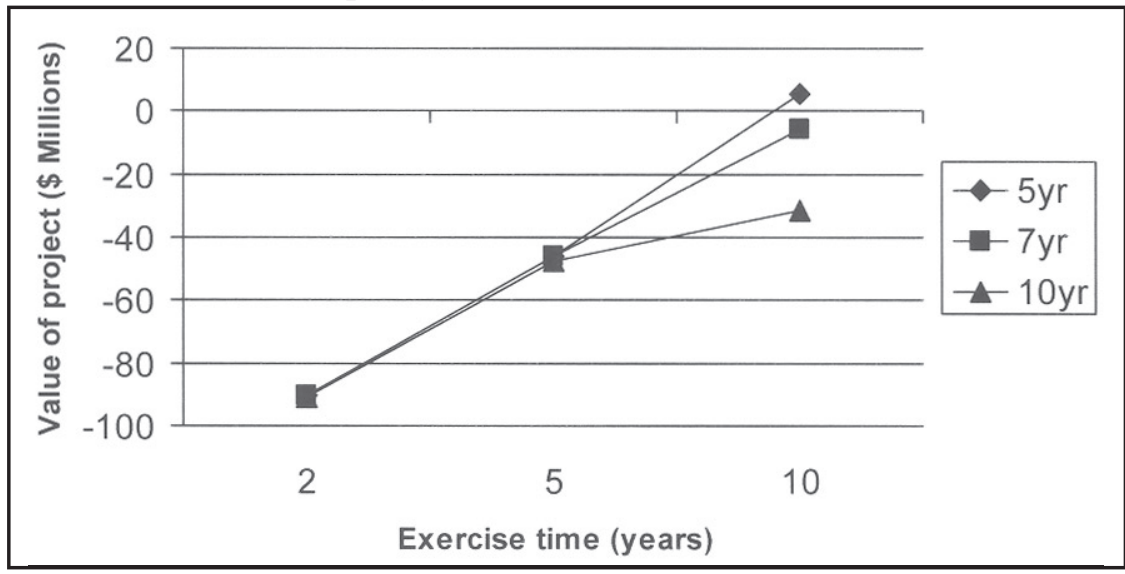

Figure 12: Value of Flexibility for Strategies that Consider $75 \%$ Capacity Increase and 5, 7, and 10 Years to Increase Capacity

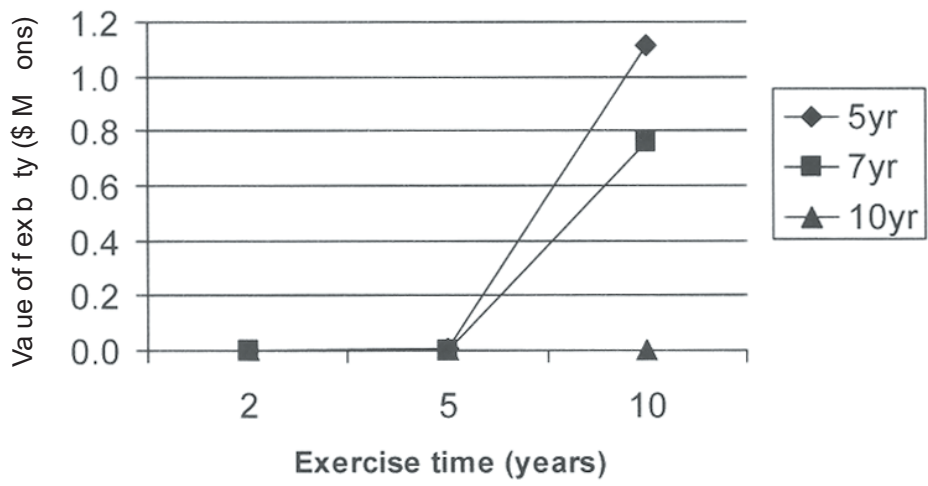


the evolution of future airport demand. The second set of data is runway construction and maintenance costs, passenger facility charges, landing fees, and airline operating costs. Estimates of passenger-demand elasticity to price and to travel time would also be required. Furthermore, any particular situations unique to the airport, such as environmental concerns and/ or community impact, should also be factored into the system dynamics model and Monte Carlo simulation.

Most of the data mentioned above should be available from airport authorities and traffic records maintained by the Federal Aviation Administration (FAA). The primary purpose of this paper is to illustrate the methodology with a generic example. A case study applied to a specific airport would be a logical extension to the work presented here.

\section{CONCLUSIONS}

\section{New Methodology to Determine the Value of Real Options}

The methodology developed here can be used to evaluate European call-like real options with uncertain stock and strike prices. If the distribution of costs and revenues can be expressed analytically, the methodology provides a closed-form solution for the value of the real option. A benefit over similar analytical approaches, such as the ones proposed by Fischer (1978) and Dixit and Pindyck (1994), is that the stock and strike price are not restricted to behaving like geometric Brownian motions. With respect to the Tufano-Moel approach, the methodology developed here would have the advantage of not being restricted to simulating the behavior of the stock and strike prices.

Another potential advantage of the methodology developed here is the possibility of managing cost for a given demand. For example, if demand is well understood, the formula developed here could be used to find the cost profile that would maximize the value of the project.

The valuation methodology developed here is very flexible and can be applied to many different situations. In particular, this methodology is suitable to evaluate projects where capital investments are large, implementation times are long, and uncertainties are large. Investments in air transportation share these qualities.

\section{Strategies with Small Capacity Increases Have Better Chances of Success}

In general, strategies with small (25\%) capacity increase are likely to have a higher expected NPV, all else equal. The intuition is that small increases in capacity are sufficient to meet the expected demand in the system modeled here. Therefore, there is no need to incur large capital expenditures and the costs can be recovered more rapidly.

\section{If Capacity Increases are Large, a Long Maturity Date is Better}

If capacity increases are medium $(50 \%)$ or large (75\%), the project developer is better off with a longer exercise date. In general, options with short maturities results in too much capacity relative to demand, thus it is difficult to recover the investment. As the exercise date recedes into the future, demand can grow to levels where the infrastructure can be better utilized.

\section{Short Times to Increase Capacity are Best}

Regardless of the capacity increase or the exercise date, a short time to increase capacity results in a higher expected value. Once the decision to increase the capacity has been made (and the resources committed), the sooner the capacity is in place, the sooner its costs can be recovered.

\section{Flexibility is Most Valuable in Uncertain Situations}

The value of flexibility depends on the performance of the inflexible project. For projects with large positive or large negative net present values, flexibility is not very valuable because there is little action that a manager can take to improve the present value of the project; however, if the NPV of the inflexible project is close to zero, flexibility can be very valuable. 


\section{Implications for the Air Transportation Industry}

The results indicate that small infrastructure increases are the best alternative to ensure profitability. However, small capacity expansions may not always be feasible in air transportation infrastructure projects, such as airports. Generally, capital expenditures imply the construction of a whole new runway which adds a considerable amount of capacity to the facility. It is in these cases that flexibility becomes very valuable because the size of the expansion implies spending a considerable amount of resources that may not be recovered if demand does not materialize. Thus, having the option to abandon the project if conditions are not favorable can be very valuable.

In addition, a short response time in the capacity delivery is very important. By being able to react quickly to the market, project managers can capture and maybe even stimulate demand that otherwise could be lost if the response time was slow. Building flexibility into their projects gives management this ability.

\section{Endnotes}

1. This discussion is based on Brealey and Myers (1996).

\section{References}

Amram, Martha and Nalin Kulatilaka. Real Options: Managing Strategic Investment in an Uncertain World. Harvard Business School Press, Boston, Massachusetts, 1999.

Black, Fischer and Myron Scholes. "The Pricing of Options and Corporate Liabilities." Journal of Political Economy 81 (3), (1973): 637-654.

Brealey, Richard A. and Stewart C. Myers. Principles of Corporate Finance. $5^{\text {th }}$ Edition. McGrawHill, New York, 1996.

Chriss, Neil A. Black-Scholes and Beyond: Option Pricing Models. Irwin, Chicago, Illinois, 1997.

Copeland, Tom and Vladimir Antikarov. Real Options: A Practitioner's Guide. Texere, New York, 2001.

de Neufville, Richard and Amedeo Odoni. Airport Systems - Planning, Design and Management. McGraw-Hill, New York, 2003.

Dixit, Avinash K. and Robert S. Pindyck. Investment Under Uncertainty. Princeton University Press, Princeton, New Jersey, 1994.

Fischer, Stanley. "Call Option Pricing when the Exercise Price is Uncertain, and the Valuation of Index Bonds.” Journal of Finance 23 (1), (1978): 169-176.

Hull, John C. Options, Futures and Other Derivatives. $4^{\text {th }}$ Edition. Prentice Hall, New Jersey, 2000 .

Miller, Bruno and John-Paul Clarke. "The Hidden Value of Air Transportation Infrastructure." Accepted for publication in Technological Forecasting and Social Change (forthcoming). 
Skinner, Steve, Alex Dichter, Paul Langley and Hendrik Sabert. "Managing Growth and Profitability Across Peaks and Troughs of the Airline Industry Cycle - An Industry Dynamics Approach.” G. Butler and M. Keller eds. Handbook of Airline Finance. New York: McGraw-Hill, (1999): 25-40.

Stonier, John E. "What is an Aircraft Purchase Option Worth? Quantifying Asset Flexibility Created Through Manufacturer Lead-Time Reductions and Product Commonality." G. Butler and M. Keller eds. Handbook of Airline Finance. New York: McGraw-Hill, (1999): 231-250.

Summa, John F. and Jonathan W. Lubow. Options on Futures: New Trading Strategies. John Wiley and Sons, New York, 2002.

Trigeorgis, Lenos. Managerial Flexibility and Strategy in Resource Allocation. MIT Press, Cambridge, Massachusetts, 1996.

Tufano, Peter and Alberto Moel. "Bidding for Antamina." Harvard Business School Case No. 9297-054, Rev. Sept. 15, 1997.

U.S. Department of Transportation, Bureau of Transportation Statistics, Office of Airline Information. Form 41. 1979-2001.

Bruno Miller is a research assistant at the International Center for Air Transportation and a doctoral candidate in air transportation systems at the Massachusetts Institute of Technology. For his Ph.D. dissertation, he is developing a methodology to support investment decisions in air transportation infrastructure under uncertainty. Miller recently finished a consulting project for the Costa Rican government diagnosing the network of local airfields and establishing a strategy for its modernization. He was recognized as the FAA Center of Excellence Student of the Year in 2003. He received his B.S. and M.S. in Aeronautics \& Astronautics from MIT and an M.S. in the Technology and Policy Program (TPP), also from MIT.

John-Paul Clarke is an associate professor of Aeronautics and Astronautics at the Massachusetts Institute of Technology (MIT) where his research and teaching address issues of optimization and robustness in airline operations, air traffic management and the environmental impact of aviation. He received his S.B. (1991), S.M. (1992) and Sc.D. (1997) from MIT, and has been a researcher at the NASA Jet Propulsion Laboratory and a visiting scholar at the Boeing Company.

Dr. Clarke was the first director of the Partnership for Air Transportation Noise and Emissions Research (PARTNER), the Center of Excellence for Aviation Noise and Aircraft Emissions Mitigation, and is an active researcher in both PARTNER and the National Center of Excellence for Aviation Operations Research (NEXTOR). His research activities at MIT are primarily conducted in the Center for Transportation and Logistics (CTL), the International Center for Air Transportation (ICAT) and the Operations Research Center (ORC). 